\title{
Combination chemotherapy with 5-fluorouracil (5FU) and 1,3-bis(2-chloro-ethyl)-1-nitrosourea (BCNU) prolongs survival of rats with dimethylhydrazine- induced colon cancer
}

\author{
M DANZI, M R LEWIN, J P CRUSE, AND C G CLARK \\ From the Department of Surgery, Faculty of Clinical Sciences, University College London, The Rayne \\ Institute, London
}

SUMmaRY The effects of combination chemotherapy with 5FU and BCNU on rats with dimethylhydrazine (DMH)-induced colon cancer were investigated in a long term survival study. Eighty Wistar rats received a colon cancer producing regimen on DMH $(40 \mathrm{mg} / \mathrm{kg}$ body weight/week, subcutaneously for 10 weeks). After presenting with signs of colonic disease, all rats underwent diagnostic laparotomy and colonoscopy when colon tumours were located, measured and the extent of the disease staged. Only animals with tumours $(n=63)$ were included and allocated to one of three tumour stages. Stage A $(n=17)$, had colonic tumours without serosal involvement; stage $B(n=28)$ had serosal involvement without metastases; stage $C(n=18)$ had serosal involvement with lymphadenopathy and/or metastases. Each group was randomly allocated into two subgroups, one serving as untreated controls while the other received 5FU ( $300 \mathrm{mg} / \mathrm{m}^{2}$ weekly intragastrically for life) together with BCNU $\left(40 \mathrm{mg} / \mathrm{m}^{2}\right.$ intraperitoneally on days 0,42 and 84 ). The effect of chemotherapy on tumour growth was measured sequentially by colonoscopy. Animals were observed until death and necropsied, when colon carcinoma was histologically confirmed and survival analysed. The results indicate that chemotherapy significantly prolongs the survival of rats with the least advanced disease (stage A) but was of no benefit to rats with locally advanced or metastatic disease (stages B and C). Furthermore, chemotherapy was associated with a significant reduction in tumour size. Survival analyses in untreated animals show that the laparotomy staging system adopted provides accurate prognostic information. This study shows that DMH-induced colon tumours are chemosensitive, and suggests that this animal model may be a valuable testing ground for new chemotherapeutic agents.

The overall prognosis for patients with colorectal cancer has remained unchanged for several decades, despite advances in diagnosis and treatment. ${ }^{1}$ As surgery is the established form of primary treatment, much research is now directed towards the development of adjuvant methods of treatment such as chemotherapy. Chemotherapeutic research to date, however, has largely involved clinical trials of empirical cytotoxic drug regimens on patients with advanced disease, and these studies have

Address for correspondence: Dr M R Lewin. Department of Surgery. The Rayne Institute. 5 University Street. London WC1E 6JJ.

Received for publication 3 February 1983 generally been unsuccessful. ${ }^{2}$ Such observations suggest that there is a need for more fundamental biological information on the effects of chemotherapy on colorectal carcinoma under controlled laboratory conditions. Progress would undoubtedly be facilitated by the availability of suitable animal models of colorectal carcinoma in which chemotherapeutic regimens could be developed and tested before their clinical application.

Two experimental approaches to the chemotherapy of colorectal cancer are currently available. The first utilises human colon tumour xenografts in 
immunodeficient mice, ${ }^{3-5}$ while the second is a syngeneic system in which colon tumours induced in mice by a chemical carcinogen (1,2dimethylhydrazine, DMH) are serially transplanted into murine hosts which then receive chemotherapy. ${ }^{6-8}$ In neither of these models are the tumours autochthonous to the host or even sited in the gastrointestinal tract, and the relevance of such systems to the human situation is debatable.

Sych et al" have recently investigated the chemotherapeutic sensitivity of a number of autochthonous rodent primary colon cancer models induced by a variety of chemical carcinogens. Their report indicates that colon tumours induced in rats by $\mathrm{DMH}$ are the most susceptible to cytotoxic agents. As the DMH model is known to closely parallel the human disease in terms of disease presentation, gross, and microscopic pathology ${ }^{10}$ and immunobiology, ${ }^{11}$ it was anticipated that $\mathrm{DMH}-$ induced colon tumours in rats would respond to chemotherapeutic drugs used in man.

The most promising chemotherapy regimens for human colorectal cancer involve combinations of fluorinated pyrimidines and nitrosoureas. ${ }^{12}$ The current study was accordingly undertaken to evaluate the effects of 5-fluorouracil (5FU) and 1,3-bis (2-chloro-ethyl)-1-nitrosourea (BCNU) on the survival of rats with $\mathrm{DMH}$-induced colon tumours and on the growth of the induced tumours.

\section{Methods}

\section{MATERIALS}

The experimental design is summarised in Figure 1.

\section{ANIMALS AND CARCINOGEN TREATMENT}

Eighty outbred female Wistar rats (purchased from A Tuck \& Sons, Battlesbridge, Essex, UK) ranging in weight from $40-50 \mathrm{~g}$, were weaned on to a standard laboratory pellet diet (formula 41B, E Dixon \& Sons, Ware, Herts, UK) and water, ad libitum and remained on this diet for the entire experiment.

After two weeks acclimatisation, all rats received a course of DMH dihydrochloride (Aldrich Chemical Company, Gillingham, Dorset, UK) at a dosage of $40 \mathrm{mg} / \mathrm{kg}$ body weight/rat/week subcutaneously for 10 weeks. DMH was prepared according to the method of Filipe. ${ }^{12}$ The animals were housed in temperature controlled quarters in subgroups of five in suspended cages which had open mesh wire floors designed to prevent coprophagia. They were weighed weekly and inspected daily for signs of illness or colonic disease (for example, rectal bleeding with positive faecal occult blood test, tumour prolapse per rectum, diarrhoea, ascites, or colonic obstruction with abdominal distension).

TUMOUR DIAGNOSIS AND STAGING

Animals with DMH-induced colon cancer characteristically develop multiple tumours and each tumour is at a different histological stage. ${ }^{13}$ As Peto $^{14}$ has pointed out the heterogeneity of histological stages of malignancy within each animal makes it impossible to accurately classify the extent of the disease in each animal as a whole. Comparisons of total tumour numbers between whole animals, when each tumour within each animal is at a different histological stage, are thus of doubtful validity. Consequently, for the purpose of this experiment, animals were staged with reference to a single index tumour, defined as the largest macroscopically identifiable colon tumour.

By the 19th week, the majority of animals were exhibiting signs of colonic disease and all rats then had a staging laparotomy and diagnostic colonoscopy under nitrous oxide and halothane anaesthesia. At laparotomy the bowel was palpated (without opening), the location and size of colonic tumours recorded and the presence of serosal tethering noted. The abdominal cavity was examined for evidence of metastases (to lymph nodes, omentum, peritoneum, and liver). Only animals with visible and palpable colonic tumours $(n=63)$ were included in the study.

Under the same anaesthetic, colonoscopy was performed using an Olympus fibreoptic paediatric bronchoscope. The bronchoscope carried, on its distal end, a wire loop with two cross wires of known dimensions. In each animal the index tumour was located and its exact distance from the anal verge measured. This was to ensure that the individual index tumour in each animal could be identified at subsequent colonoscopies and at necropsy. Each index tumour also had its two maximum perpendicular diameters measured using the wire loop. Tumour areas were calculated from these measurements using the formula for surface area of an ellipse $\left(\pi r_{1} r_{2}\right)$.

The 63 animals with visible and palpable colon tumours were allocated to one of three tumour stages according to the macroscopic assessment of the largest and most advanced colonic tumour in each animal (the index tumour). Stage $A$ rats $(n=17)$ had index tumours with no visible signs of serosal involvement; stage $B(n=28)$ index tumours showed serosal involvement with puckering and dimpling but no evidence of extracolonic metastases; stage $C(n=18)$ had index tumours with serosal involvement together with regional lymphadenopathy and/or distant metastases (to omentum, 
EXPERIMENTAL DESIGN

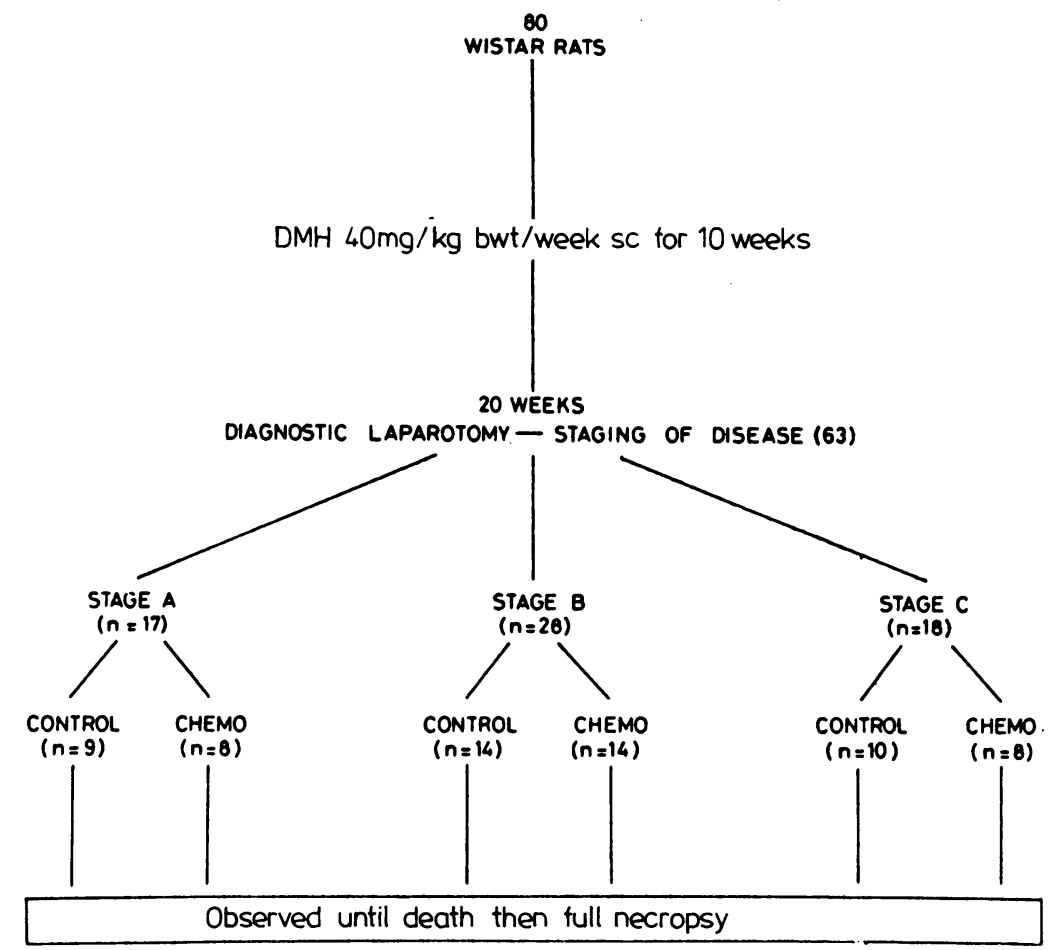

DMH $40 \mathrm{mg} / \mathrm{kg}$ bwt/week sc for 10 weeks

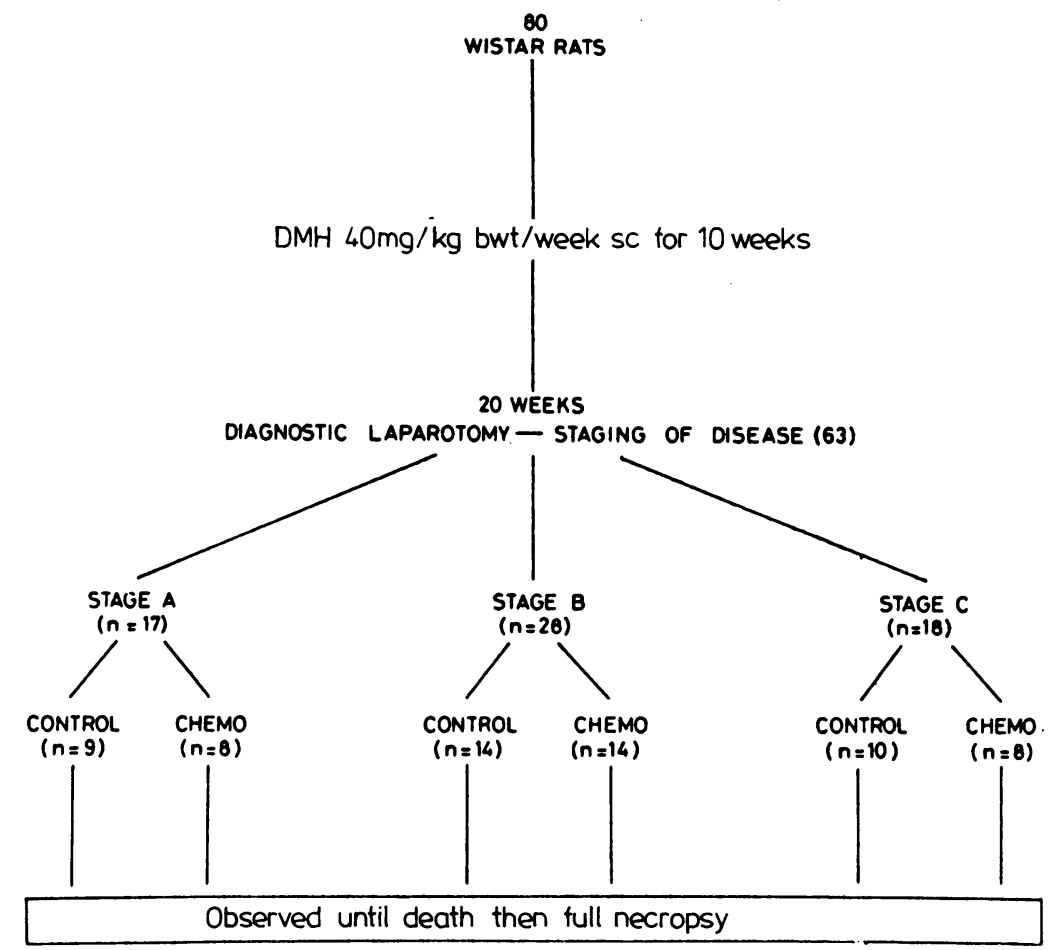

Fig. 1 Experimental design

peritoneum, or liver). Each group was then randomly allocated into two subgroups, one serving as untreated controls while the other received chemotherapy.

\section{CHEMOTHERAPY}

5-fluorouracil (5FU) is a pyrimidine antagonist which belongs to the antimetabolite group of tumour inhibiting compounds. Its efficacy against human colorectal cancer, given either singly or in combination with nitrosoureas is well documented ${ }^{2}$ and it has been shown to be active against DMHinduced transplanted mouse colon tumours ${ }^{8}$ and against primary DMH-induced rat colon tumours. ${ }^{9}$

1,3-bis(2-chloro-ethyl)-1-nitrosourea (BCNU) is a nitrosourea compound which inhibits protein, DNA and RNA synthesis. ${ }^{15}$ It has been used, in combination with 5FU in man, but there are no previous reports of its use in DMH-treated rats. The therapeutic dosage and regimen of usage of these drugs were chosen on the basis of a series of toxicity studies carried out in our laboratory during pilot studies in tumour-free rats. The doses were given on the basis of a body weight/surface area nomogram according to the method of Freireich et al. ${ }^{16} 5 \mathrm{FU}$, dissolved in saline, was given in doses of $300 \mathrm{mg} / \mathrm{m}^{2}$ weekly, intragastrically for life. BCNU, dissolved in camphor and absolute ethanol according to the method of Zeller et $a l^{17}$ was injected intraperitoneally on days 0,42 and 84 in doses of 40 $\mathrm{mg} / \mathrm{m}^{2}$.

\section{ASSESSMENT OF TUMOUR RESPONSE}

The effect of chemotherapy on the index tumour in each rat was serially assessed at $\mathbf{3 0}$ day intervals by means of fibreoptic colonoscopy under nitrous oxide/halothane anaesthesia. At colonoscopy, the index tumour was relocated by its distance from the anal verge and measured as described before; sequential tumour area data were calculated from these measurements.

\section{SUBSEQUENT OBSERVATION AND NECROPSY}

The animals were weighed and inspected daily for signs of illness or colonic disease as described before. When moribund, animals were isolated to prevent cannibalisation and either died spontaneously or were painlessly killed when they 
fulfilled objective criteria. ${ }^{18}$ Complete necropsies and the selection of specimens for histological examination were carried out on every animal. Colon tumours were only classified as carcinoma if there was invasion across the muscularis mucosae, according to the criteria of Morson. ${ }^{19}$

\section{EXPERIMENTAL EVALUATION AND STATISTICAL} ANALYSIS OF DATA

The experiment was evaluated by a statistical comparison of overall survival (irrespective of cause of death) between treated and untreated animals with the same stage of disease, and by comparisons between stages, using the log rank method of Peto et al. ${ }^{20}$ Sequential measurements of tumour size and calculated tumour area data were compared between groups of treated and untreated animals with the same stage of disease, and between rats of different stages, using the Wilcoxon's rank sum test and the Wilcoxon's paired rank sum test. ${ }^{21}$

\section{Results}

The data were analysed after the last rat had died, 240 days after the staging laparotomy and are summarised in Figure 2 and Table 1.

\section{NECROPSY AND HISTOPATHOLOGY}

At necropsy, the index tumour in every rat was relocated and histologically confirmed as carcinoma. Many of the tumours in the chemotherapy group were noted to contain varying degrees of necrosis, but the incidence of necrotic tumours was not significantly different when compared with untreated controls. There was no significant difference in the incidence of metastases at necropsy

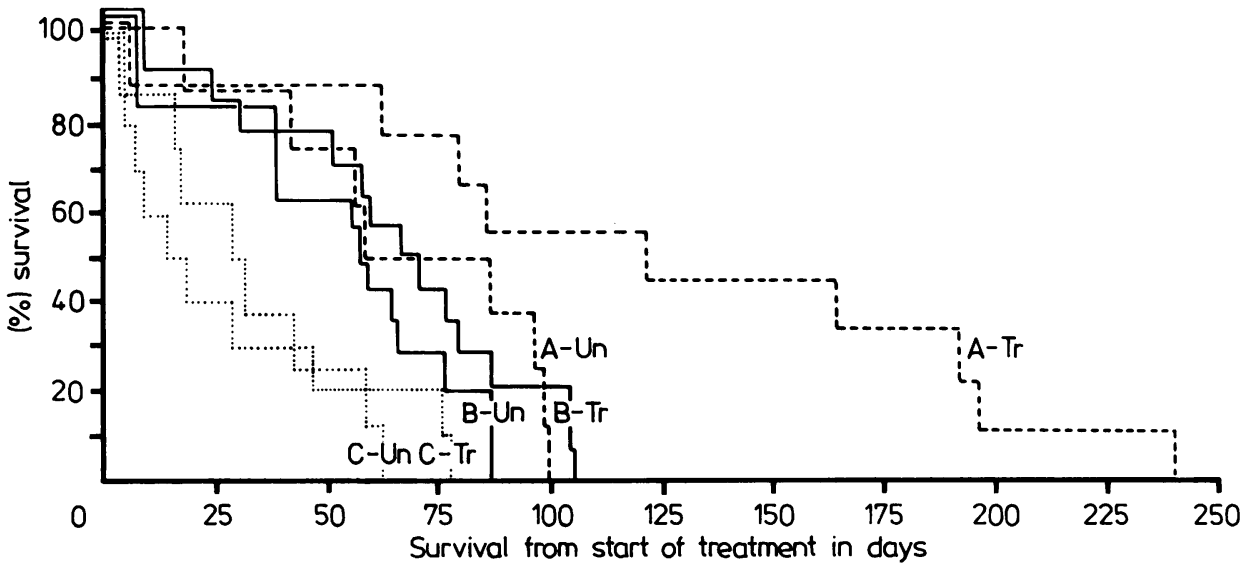

Fig. 2 Life table of the probability of survival as a function of time from start of treatment

\begin{tabular}{|c|c|c|c|c|c|c|}
\hline $\begin{array}{l}\text { Stages and } \\
\text { treatment }\end{array}$ & $\begin{array}{l}\text { Observed } \\
\text { survival }(O)\end{array}$ & $\begin{array}{l}\text { Expected } \\
\text { survival }(E)\end{array}$ & Ratio $O / E$ & $X^{2}$ & $\begin{array}{l}\text { Degrees of } \\
\text { Freedom }\end{array}$ & Probability $p^{*}$ \\
\hline $\begin{array}{l}\text { A } \\
\text { B Treated } \\
\text { C }\end{array}$ & $\begin{array}{r}9 \\
14 \\
10\end{array}$ & $\begin{array}{r}17.06 \\
12.24 \\
\ldots \quad 3.70\end{array}$ & $\begin{array}{l}0.53 \\
1 \cdot 14 \\
2 \cdot 70\end{array}$ & 14.79 & 2 & $<0.0003$ \\
\hline $\begin{array}{l}\text { A } \\
\text { B Untreated } \\
\text { C }\end{array}$ & $\begin{array}{r}8 \\
14 \\
8\end{array}$ & $\begin{array}{r}12.96 \\
13.78 \\
3.26\end{array}$ & $\begin{array}{l}0.62 \\
1.02 \\
2 \cdot 45\end{array}$ & 8.79 & 2 & $<0.003$ \\
\hline $\begin{array}{l}\text { A Treated } \\
\text { A Untreated }\end{array}$ & $\begin{array}{l}9 \\
8\end{array}$ & $\begin{array}{r}12 \cdot 38 \\
4.62\end{array}$ & $\begin{array}{l}0.73 \\
1.73\end{array}$ & 3.40 & 1 & $<0.05$ \\
\hline $\begin{array}{l}\text { B Treated } \\
\text { B Untreated }\end{array}$ & $\begin{array}{l}14 \\
14\end{array}$ & $\begin{array}{l}16 \cdot 66 \\
11 \cdot 34\end{array}$ & $\begin{array}{l}0 \cdot 84 \\
1 \cdot 23\end{array}$ & 1.05 & 1 & NS \\
\hline $\begin{array}{l}\text { C Treated } \\
C \text { Untreated }\end{array}$ & $\begin{array}{r}10 \\
8\end{array}$ & $\begin{array}{r}10 \cdot 12 \\
7 \cdot 88\end{array}$ & $\begin{array}{l}0.99 \\
1.01\end{array}$ & 0.003 & 1 & NS \\
\hline
\end{tabular}

* 1 Tail; $\operatorname{Tr}=$ treated; Un $=$ untreated 
Table 1 Median survival in days between treated and untreated rats within each of the three tumour stages

\begin{tabular}{llll}
\hline & \multicolumn{2}{c}{ Median (range) survival (d) } & \\
\cline { 2 - 3 } Stage & Treated & Untreated & $\begin{array}{c}\text { Treated } \\
\text { vs Untreated }\end{array}$ \\
\hline A & $121(6-240)$ & $72(18-99)$ & p $<0.05$ \\
B & $68(5-105)$ & $61(6-86)$ & NS \\
C & $16(6-77)$ & $30(6-62)$ & NS \\
\hline
\end{tabular}

in treated and untreated groups of animals with the same stage of disease.

SURVIVAL

Treated rats with stage A disease had a significantly improved survival $(\mathrm{p}<0.05)$ compared with untreated rats with the same stage disease. (See Fig. 2). There was no difference, however, in survival between treated and untreated rats in stages $B$ and C. Furthermore, treated rats with stage A disease had a significantly improved survival compared with treated rats with stage $B(p<0.01)$ and stage $C$ $(\mathrm{p}<0.005)$ disease.

In order to test the prognostic accuracy of the staging laparotomy the survivals of all the untreated groups were compared. These analyses show that untreated rats with stage $A$ disease survived significantly longer than untreated rats with stage B $(\mathrm{p}<0.05)$ which in turn survived significantly longer than untreated rats with stage $C(p<0 \cdot 025)$.

TUMOUR RESPONSE

Tumour response to chemotherapy is detailed in Table 2 and Figure 3, and shows that the median tumour area in stage A treated rats was significantly smaller than the tumour area in untreated rats with the same stage of disease at 30 and 60 days $(p<0 \cdot 01)$

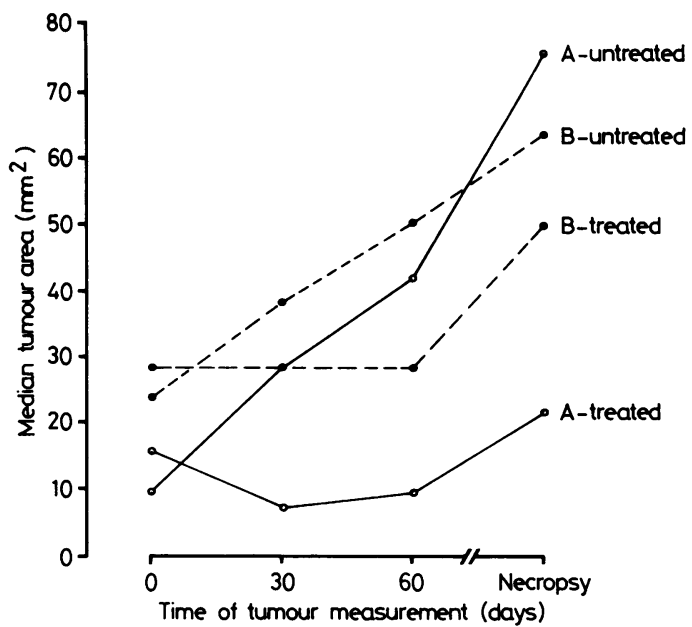

Fig. 3 Changes in median tumour area with time in both treated and untreated rats with tumour stages $A$ and $B$

and at necropsy $(p<0 \cdot 02)$. A similar trend was also seen in animals with stage $B$ disease where median tumour areas in treated rats were significantly smaller than tumour areas in untreated rats at 30 days $(\mathrm{p}<0.01)$, at 60 days $(\mathrm{p}<0.02)$ and at necropsy $(\mathrm{p}<0.01)$. As the majority of stage $\mathrm{C}$ animals died before the first colonoscopic examination (see Table 1), sequential tumour assessment was not possible in this group.

\section{Discussion}

The salient finding to emerge from this study is that $\mathrm{DMH}$-induced colon cancer in rats is responsive to chemotherapy with agents used clinically in man. The combination of $5 \mathrm{FU}$ and $\mathrm{BCNU}$ is successful in

Table 2 Sequential comparison of tumour areas between treated and untreated animals within each of the three tumour stages

\begin{tabular}{|c|c|c|c|c|c|c|c|c|c|}
\hline \multirow[b]{3}{*}{ Time of tumour measurement } & \multicolumn{9}{|c|}{ Median tumour area (range) $\mathrm{mm}^{2}$} \\
\hline & \multicolumn{3}{|l|}{ Stage A } & \multicolumn{3}{|l|}{ Stage $B$} & \multicolumn{3}{|l|}{ Stage $C$} \\
\hline & Treated & Untreated & $P$ & Treated & Untreated & $P$ & Treated & Untreated & $P$ \\
\hline Laparotomy & $\begin{array}{l}15 \cdot 7 \\
(4 \cdot 7-23 \cdot 6)\end{array}$ & $\begin{array}{l}9 \cdot 4 \\
(7 \cdot 1-28 \cdot 3)\end{array}$ & NS & $\begin{array}{l}28 \cdot 3 \\
(23 \cdot 6-38 \cdot 5)\end{array}$ & $\begin{array}{l}23 \cdot 6 \\
(23 \cdot 6-33 \cdot 6)\end{array}$ & $<0.05$ & $\begin{array}{l}38 \cdot 5 \\
(23 \cdot 6-78 \cdot 6)\end{array}$ & $\begin{array}{l}33 \cdot 4 \\
(7 \cdot 1-176 \cdot 8)\end{array}$ & NS \\
\hline 30 Days & $\begin{array}{l}7 \cdot 1 \\
(4 \cdot 7-12 \cdot 6)\end{array}$ & $\begin{array}{l}28 \cdot 3 \\
(9 \cdot 4-38 \cdot 5)\end{array}$ & $<0.01$ & $\begin{array}{l}28 \cdot 3 \\
(15 \cdot 7-38 \cdot 5)\end{array}$ & $\begin{array}{l}38 \cdot 5 \\
(33 \cdot 0-44 \cdot 0)\end{array}$ & $<0.01$ & $\star$ & $\star$ & $\star$ \\
\hline 60 Days & $\begin{array}{l}9 \cdot 4 \\
(7 \cdot 1-12 \cdot 6)\end{array}$ & $\begin{array}{l}41 \cdot 8 \\
(19 \cdot 6-50 \cdot 3)\end{array}$ & $<0 \cdot 01$ & $\begin{array}{l}28 \cdot 3 \\
(18 \cdot 8-50 \cdot 3)\end{array}$ & $\begin{array}{l}50 \cdot 3 \\
(44 \cdot 0-50 \cdot 3)\end{array}$ & $<0 \cdot 02$ & $\star$ & $\star$ & $\star$ \\
\hline Necropsy & $\begin{array}{l}21 \cdot 6 \\
(7 \cdot 1-62 \cdot 9)\end{array}$ & $\begin{array}{l}75 \cdot 5 \\
(44 \cdot 0-143 \cdot 0)\end{array}$ & $<0 \cdot 02$ & $\begin{array}{l}49 \cdot 9 \\
(28 \cdot 3-70 \cdot 7)\end{array}$ & $\begin{array}{l}63 \cdot 3 \\
(56 \cdot 5-95 \cdot 0)\end{array}$ & $<0.01$ & $\begin{array}{l}78 \cdot 6 \\
(38 \cdot 5-122 \cdot 6)\end{array}$ & $\begin{array}{l}78 \cdot 6 \\
(31 \cdot 4-227 \cdot 1)\end{array}$ & NS \\
\hline
\end{tabular}

$\star$ The majority of Stage C animals died before the first colonoscopic examination (See Table 1). 
prolonging the survival of rats with the least advanced disease (stage A), and, as in man $^{2}$ appears to have no beneficial effect on animals with locally advanced or metastatic disease. Furthermore, chemotherapy is associated with a significant reduction in the size of the primary tumours in treated animals with stages $\mathrm{A}$ and $\mathrm{B}$. In a similar study a reduction in tumour volume was observed in $5 \mathrm{FU}$ and BCNU treated mice bearing human colon tumour xenografts derived from patients with Duke's A and B carcinomas. ${ }^{22}$ It is probable that the improved survival observed is directly attributable to the reduced growth of colon tumours in treated animals.

Two additional experimental observations are of interest. The first is that the use of fibreoptic colonoscopy as developed in this experiment provides an excellent method of diagnosing and sequentially measuring the effect of chemotherapy on the induced colon tumours. Although colonoscopy has been used for tumour diagnosis in an animal colon cancer model, ${ }^{23}$ the sequential assessment of the effect of chemotherapy on colon tumour growth in vivo has not hitherto been possible. Secondly, the laparotomy staging system adopted in this experiment, which is analagous to the Duke's staging system for human colorectal cancer ${ }^{24}$ provides accurate prognostic information. In other words, animals with less advanced disease (stage A) survive significantly longer than those with more advanced disease (stages $B$ and $C$ ), irrespective of treatment. This is in agreement with the findings of Sych et al and indicates that the survival of rats with colon cancer closely parallels that of humans with this disease in being dependent upon the extent of disease at the time of diagnosis.

The DMH model is theoretically superior to the human-mouse xenograft ${ }^{3-5}$ and the transplantable mouse $e^{6-8}$ models in that the induced colon tumours arise autochthonously in the colons of their hosts. The model only incompletely parallels the clinical situation, however, in that chemotherapy in the model is given to rats with primary colon tumours in situ, while patients generally receive chemotherapy after surgical resection of their primary disease. Nevertheless, the fact that clinically used drugs such as $5 \mathrm{FU}$ and $\mathrm{BCNU}$ inhibit the growth of $\mathrm{DMH}$ induced colon tumours and prolong the survival of their rodent hosts suggests a parallel in tumour sensitivity. With further refinements, such as resection of the primary disease by subtotal colectomy ${ }^{25}$ so as to mimic the human situation more accurately, the DMH-induced rat colon cancer model may prove a valuable additional testing ground for the chemotherapy of human colorectal cancer.
This study was presented to the BSG Spring Meeting, Norwich, 24-26 March 1982.

We thank Miss Sue Harper for typing the manuscript and Peter Luther for photography. MD gratefully acknowledges support by the Consigelio Nazionale Ricerche, Italy (No. CNR-52067).

\section{References}

1 Medical Research Council. Review of gastric and colorectal cancers. London: Medical Research Council, 1977.

2 Moertel CG. Chemotherapy of gastrointestinal cancer. $N$ Engl J Med 1978; 299: 1049-52.

3 Tibbetts LM, Chu MY, Hager JC, Dexter DL, Calabresi P. Chemotherapy of cell-line derived human colon carcinomas in mice immunosuppressed with antithymocyte serum. Cancer 1977; 40: 2651-9.

4 Lamberton LF, Steel GG. Growth kinetics of human large bowel cancer growing in immune-deprived mice and some chemotherapeutic observations. Cancer 1975; 36: 2431-6.

5 Cobb LM, Mitchley BCV. Development of a method for assessing the antitumour activity of chemotherapeutic agents using human tumour xenografts. Cancer Chemother Rep 1974; 58: 645-51.

6 Ball CR, Double JA. Transplantable colon tumours as chemotherapy screening models. Cancer 1975; 36: 2437-40.

7 Griswold DP, Corbett TH. A colon tumour model for anticancer agent evaluation. Cancer 1975; 36: 2411-44.

8 Corbett TH, Griswold DP, Roberts BJ, Peckham JC, Schabel FM. Evaluation of single agents and combinations of chemotherapeutic agents in mouse colon carcinomas. Cancer 1977; 40: 2660-80.

9 Sych F, Habs M, Schmähl D. Chemotherapy studies in autochthonous rat tumours: intestinal cancer. Z Krebsforsch 1978; 92: 105-17.

10 LaMont JT, O'Gorman TA. Experimental colon cancer. Gastroenterology 1978; 75: 1157-69.

11 Sjogren HO, Steele G. The immunology of large bowel carcinoma in a rat model. Cancer 1975; 36: 2469-71.

12 Filipe MI. Mucous secretion in rat colonic mucosa during carcinogenesis induced by dimethylhydrazine. A morphological and histochemical study. Br J Cancer 1975; 32: 60-77.

13 Pozharisski KM. Morphology and morphogenesis of experimental epithelial tumours of the intestine. $J$ Natl Cancer Inst 1975; 54: 1115-35.

14 Peto R. In: Hiatt HH, et al eds. Origins of human cancer. New York: Cold Spring Harbour Laboratories, 1977: 1403-38.

15 Schabel FM: Nitrosoureas: A review of experimental antitumour activity. Cancer Treatment Rep 1976; 60: 665-98.

16 Freireich GJ, Gehan EA, Rall DP, Schmidt LH, 
Skipper HE. Quantitative comparison of toxicity of anticancer agents in mouse, rat, dog, monkey and man. Cancer Chemother Rep 1966; 50: 219-44.

17 Zeller WJ, Eisenbrand G, Fiebig HH. Chemotherapeutic activity of 2-chloro-ethyl-nitrosourea in rats L5222 leukaemia: Comparison of bifunctional and water soluble derivatives with 1,3-bis-(2-chloro-ethyl)1-nitrosourea. J Natl Cancer Inst 1978; 60: 345-8.

18 Cruse JP. Lewin MR. Clark CG. Corynebacterium parvum enhances colonic cancer in dimethylhydrazine-treated rats. Br J Cancer 1978; 37: 639-43.

19 Morson BC. Polyps and cancer of the large bowel. In Yardley J. ed. The gastrointestinal tract. Baltimore: Williams and Wilkins, 1977: 101-8.

20 Peto R, et al. Guidelines for simple, sensitive significance tests for carcinogenic effects in long-term animal experiments, In: IARC monographs on the evaluation of carcinogenic risk of chemicals to humans,
Lyon: International Agency for Research on Cancer, 1980: suppl. 2; 311-426.

21 Siegel S. Nonparametric statistics for the behavioral sciences. Tokyo: McGraw-Hill, 1956: 96-104.

22 Schmitz R, Hueper J, Pichlmayr R. Studies in an animal model on the effectiveness of adjuvant chemotherapy with $5 \mathrm{FU}$ and $\mathrm{BCNU}$ in cases of colorectal adenocarcinoma. J Cancer Res Clin Oncol 1981; 100: 213-20.

23 Narisawa T, Wong C-Q, Weisburger JH. Evaluation of endoscopic examination of colon tumours in rats. $A m \mathrm{~J}$ Dig Dis 1975; 20: 928-34.

24 Dukes CE, Bussey HJR. The spread of rectal cancer and its effect on prognosis. $\mathrm{Br} J$ Cancer 1958; 12: 309-20.

25 Ferulano GP, Cruse JP, Lewin MR, Clark CG. Sutotal colectomy in the dimethylhydrazine-treated rat. Eur Surg Res 1982; 14: 393-400. 